\title{
Efficacy and prognosis of CT-guided of 125I radioactive seeds implantation brachytherapy as salvage treatment for recurrent nasopharyngeal carcinoma after external beam radiotherapy-A long-term experience at a single institution
}

\author{
xuemin $\mathrm{li}^{1}$, Yuliang Jiang ${ }^{1}$, Zhe $\mathrm{Ji}^{1}$, Ran Peng${ }^{1}$, Fuxin Guo ${ }^{1}$, Yi Chen ${ }^{1}$, Shuhua Wei ${ }^{1}$, \\ Haitao Haitao Sun ${ }^{1}$, Jinghong Fan ${ }^{1}$, Weiyan $\mathrm{Li}^{1}$, and Junjie Wang ${ }^{1}$ \\ ${ }^{1}$ Peking University Third Hospital
}

November 30, 2020

\begin{abstract}
Background: To assess the efficacy and prognosis of computed tomography (CT)-guided 125I radioactive seeds implantation brachytherapy (RSI-BT) for recurrent nasopharyngeal carcinoma (NPC) after external beam radiotherapy (EBRT). Methods: Thirty-one patients with recurrent NPC (forty-one lesions) after EBRT from February 2003 to January 2019 were enrolled in this retrospective study. The work-follow of CT-guidance RSI-BT was: indication selection, patient set-up and immobilization on CT couch, CT-simulation, preoperative planning, prescription doses (PD) definition of 110-160Gy, seed implantation, postoperative dosimetric evaluation and postoperative follow-up. Median radioactivity of RSI was 0.43 (range 0.22-0.79, average 0.61) mCi. Median actuarial number of 125I seeds was 24 (range 3-83, average 37). Median value of post-operative D90 was 118.5 (range 62.4-246, average 136.2) Gy. Local control (LC) and overall survival (OS) were investigated for their relationship with the prognosis. The adverse events were evaluated by the Radiation Therapy Oncology Group (RTOG) classification criteria. Results: Median follow-up was 41.9 (range 2.1-60.2, average 44.1) months. Median LC was 35.8 (range 2.1-60.2, average 34.9) months. LC at 1-, 3- and 5-year was $71.3 \%, 41.9 \%$ and $27.9 \%$, respectively. Median OS was 22.6 (range 2.1 60.2, average 27.1) months. OS at 1-, 3- and 5-years was $57.7 \%, 23.8 \%$ and $11.9 \%$, respectively. Univariate analysis suggested that sex $(\mathrm{P}=0.037)$ and frequency of previous EBRT $(\mathrm{P}=0.001)$ were prognostic factors influencing LC. Moreover, univariate analysis also suggested that frequency of previous EBRT $(\mathrm{P}=0.012)$ was prognostic factors influencing OS. Prevalence of side effects ([?]grade 3) was 6.5\%. Conclusion: 125I RSI-BT was a safe and feasible salvage treatment for recurrent NPC after EBRT. Key words: recurrent nasopharyngeal carcinoma; External beam radiotherapy; 125I seed implantation brachytherapy; overall survival; local control; side effects.
\end{abstract}

\section{Original Article}

Efficacy and prognosis of CT-guided of ${ }^{125} \mathrm{I}$ radioactive seeds implantation brachytherapy as salvage treatment for recurrent nasopharyngeal carcinoma after external beam radiotherapy

\section{-A long-term experience at a single institution}

\begin{abstract}
Background : To assess the efficacy and prognosis of computed tomography (CT)-guided ${ }^{125}$ I radioactive seeds implantation brachytherapy (RSI-BT) for recurrent nasopharyngeal carcinoma (NPC) after external beam radiotherapy $(\mathrm{EBRT})$.

Methods : Thirty-one patients with recurrent NPC (forty-one lesions) after EBRT from February 2003 to January 2019 were enrolled in this retrospective study. The work-follow of CT-guidance RSI-BT was:
\end{abstract}


indication selection, patient set-up and immobilization on CT couch, CT-simulation, preoperative planning, prescription doses (PD) definition of 110-160Gy, seed implantation, postoperative dosimetric evaluation and postoperative follow-up. Median radioactivity of RSI was 0.43 (range 0.22-0.79, average 0.61 ) mCi. Median actuarial number of ${ }^{125} \mathrm{I}$ seeds was 24 (range 3-83, average 37). Median value of post-operative D90 was 118.5 (range 62.4-246, average 136.2) Gy. Local control (LC) and overall survival (OS) were investigated for their relationship with the prognosis. The adverse events were evaluated by the Radiation Therapy Oncology Group (RTOG) classification criteria.

Results : Median follow-up was 41.9 (range 2.1-60.2, average 44.1) months. Median LC was 35.8 (range 2.1-60.2, average 34.9) months. LC at 1-, 3 - and 5-year was $71.3 \%, 41.9 \%$ and $27.9 \%$, respectively. Median OS was 22.6 (range 2.1 60.2, average 27.1) months. OS at 1-, 3- and 5-years was $57.7 \%, 23.8 \%$ and $11.9 \%$, respectively. Univariate analysis suggested that sex $(\mathrm{P}=0.037)$ and frequency of previous EBRT $(\mathrm{P}=0.001)$ were prognostic factors influencing LC. Moreover, univariate analysis also suggested that frequency of previous EBRT $(\mathrm{P}=0.012)$ was prognostic factors influencing OS. Prevalence of side effects ([?]grade 3) was $6.5 \%$.

Conclusion : ${ }^{125}$ I RSI-BT was a safe and feasible salvage treatment for recurrent NPC after EBRT.

Key words : recurrent nasopharyngeal carcinoma; External beam radiotherapy; ${ }^{125} \mathrm{I}$ seed implantation brachytherapy; overall survival; local control; side effects.

\section{Highlights:}

${ }^{125}$ I RSI-BT was a safe and feasible salvage treatment for recurrent NPC after EBRT.

Frequency of previous EBRT was a prognostic factor influencing LC and OS.

Patients with recurrent NPC after EBRT, especially those treated with re-irradiation might benefit from ${ }^{125}$ I RSI-BT.

\section{Introduction}

Nasopharyngeal carcinoma (NPC) was one of the most common head and neck malignancies and was prevalent in southern China. The International Cancer Research Center reported that in 2012 the worldwide incidence of NPC was 12/100,000, whereas new cases of NPC in China accounted for $53.5 \%$ of the worldwide incidence $^{12}$.

EBRT was first-line treatment modality for NPC. Approximately $20-40 \%$ of patients suffered from recurrence after $\mathrm{EBRT}^{3-5}$. With the popularity of precise EBRT and comprehensive treatment (EBRT combined with chemotherapy), the efficacy of treatment has improved greatly with a 5 -year recurrence-free survival rate of 83.0-91.8\% ${ }^{6-8}$. However, advanced NPC carried a poor prognosis if recurrence occurred. Thus, exploring a high efficient treatment for recurrent NPC was necessary.

Over the past few decades, improvement of surgical skills, re-irradiation, chemotherapy and other treatments have contributed to salvage treatment for recurrent NPC. For patients with early-stage recurrence, surgery could be an alternative, which would resect radiation-resistant tumors and avoid reirradiation damage as much as possible. It has been reported that 5-year LC and OS after tumor resection were $43-74 \%$ and $47-62 \%$ respectively ${ }^{9-13}$. However, most patients recurred with late-stage disease which usually unresectable ${ }^{14-17}$.

Reirradiation was one of the most common salvage treatments for recurrent $\mathrm{NPC}^{18}$. Previous studies showed that the recurrent NPC patients treated with re-irradiation, LC and OS at 3 years could reach $70-89 \%$ and $46-58 \%$, respectively ${ }^{19-22}$. However, about $30-70 \%$ of patients were likely to develop severe (grade $3-5$ ) complications ${ }^{202123-25}$. Moreover, some patients might die of fatal complications, such as necrosis of the temporal lobe necrosis or carotid blowout ${ }^{26}$.

${ }^{125}$ I RSI-BT, as a local treatment, was characterized by high local dose, sharp fall-off of dose curve and little unexpected radiation effects on adjacent normal tissues. ${ }^{125}$ I RSI-BT has been considered as salvage treatment for some types of recurrent cancer, such as rectal cancer ${ }^{27}$. The advantages of CT-guidance 
punctures were: (1) high resolution of CT scans; (2) high precision for needles into puncture position; (3) minimal invasion and fast recovery. However, few studies of ${ }^{125}$ I RSI-BT against recurrent NPC have reported. In this study we investigated the efficacy and prognosis of ${ }^{125}$ I RSI-BT treatment of recurrent NPC with a long-term follow-up.

\section{Materials and Methods}

\subsection{Patients}

There are 31 patients (41 lesions) with recurrent NPC after EBRT from February 2003 to January 2019 reviewed retrospectively, among which 11 patients (35.5\%) treated with twice or more times EBRT and the median previous radiation doses were 71.9 (range 60-160) Gy. 17 patients with CT-guided RSI-BT only and 14 of patients with CT-guidance combined with 3D-PT assistant RSI-BT were performed under standard operating procedure in our institution. Informed consent was signed by each patient before the treatment.

\subsection{Inclusion and exclusion criteria}

The inclusion criteria were as follows: (1) NPC confirmed by pathology; (2) relapse after EBRT and unable or rejecting to undergo surgery or re-irradiation; (3) tumor diameter [?]7cm; (4)pre-plan shown a feasible needle pathway to avoid bones, large blood vessels or organs at risk (OARs); (5) Karnofsky Performance Status (KPS) [?]60; (6) expected survival [?]3 months. The exclusion criteria were as follows: (1) severe bleeding tendency; (2) immunocompromised with acute infection or chronic active infection; (3) patient with conditions intolerant to minimal invasive procedure/surgery such as severe cardiopulmonary insufficiency or liver and kidney; (4) contraindication to anesthesia; (5) uncontrolled multiple metastases.

\section{$2.3^{125}$ I RSI-BT}

All patients underwent standard RSI-BT procedure (Fig 1). Pre-operative CT scans (slice thickness 2.5-5 $\mathrm{mm}$ with contrast) was carried out and images were transmitted to Brachytherapy Treatment Planning System (BT-TPS) (Beijing Astro Technology, Beijing, China). The needle-puncture pathway was designed on BT-TPS. Radioactivity and number of seeds were calculated according to prescription doses (PD) design. Individualized template was made by three-dimensional-printing techniques (3D-PT). Finally, a digital information of needles channels on BT-TPS for pre-operative plan was transferred into 3D-pinting software and reconstruction.

Patients were usually positioned supine according to the tumor sites. After the induction of local anesthesia, the operator chose the best layer and angle for needle puncture assisted or not by 3D-PT based on the preoperative plan and followed by needle insertion. CT scans to verify the needles position and direction, the operator optimized the angle and depth of the needle by real-time CT scan to conform the pre-operative plan. Then, seeds were implanted using a Mick ${ }^{\circledR}$ Applicator (Mick Radio Nuclear Instruments, Mount Vernon, NY, USA) according to pre-plan. Finally, CT was undertaken immediately following seeds implantation to check the actual distribution of $125 \mathrm{I}$ seeds and, if necessary, more seeds would be implanted for doses distribution in the targets as pre-plan requirements.

\subsection{Follow-up}

Patients were followed up every 3-6 months within 5 years after surgery, and once a year thereafter. Followup was conducted by telephone, outpatient appointment or hospitalization. Follow-up information included symptoms, physical examination, laboratory-test data and imaging examinations.

\subsection{End points and their definition}

The first end points included LC. LC was defined as the interval from the date of RSI-BT to the date of local progression. The second end points included OS and treatment-related toxicity. OS was defined as interval from the date of RSI-BT to the date of death for any cause. Treatment-related toxicity was evaluated by the Radiation Therapy Oncology Group (RTOG) classification criteria ${ }^{28}$.

\subsection{Statistical analyses}


Statistical analyses were performed using SPSS v22.0. The Kaplan-Meier method was used to calculate LC and OS. The Cox regression model was used for univariate analysis to analyze correlation between clinical factors with LC and survival.

\section{Results}

\subsection{General information}

A total of 41 lesions in 31 patients were assessed. General information of the patients and tumors was shown on Table 1 . The median age of the study cohort was 52 (range, $25-73$, average 52.5 ) years old. $34.1 \%$ lesions $(14 / 41)$ with RSI-BT were assisted by 3D-PT. The median radioactivity of ${ }^{125}$ I radioactive seeds was 0.43 (range, $0.22-0.79$, average 0.61$) \mathrm{mCi}$. The median number of ${ }^{125} \mathrm{I}$ radioactive seeds was 24 (3-83, average 37 ). The median value of D90 was 118.5 (62.4-246, average 136.2) Gy.

\subsection{LC and Survival}

Median follow-up was 41.9 (range 2.1-60.2, average 44.0) months. In total, 16 lesions in 11 patients suffered local progression. The median duration of LC was 35.8 (range 2.1-60.2, average 34.9) months (Figure 2). LC at 1,3 and 5 years was $71.3 \%, 41.9 \%$ and $27.9 \%$, respectively. Twenty patients died: ten (50\%) due to local progression, two (10\%) due to haemorrhage, four (20\%) due to distant metastasis and four (20\%) due to non-cancer reasons (two of cachexia, one of transfusion reaction and one of pulmonary infection). The median OS was 22.6 (range, 2.1 60.2, average 27.1) months (Figure 3). OS at 1-, 3- and 5-years was 57.7\%, $23.8 \%$ and $11.9 \%$, respectively.

\subsection{Prognostic factors}

Univariate analysis suggested that sex $(\mathrm{P}=0.037)$ and frequency of previous EBRT $(\mathrm{P}=0.001)$ were prognostic factors influencing LC (Table 3). Moreover, univariate analysis also suggested that frequency of previous EBRT $(\mathrm{P}=0.012)$ was prognostic factors influencing OS (Table 4).

For patients who had received only once EBRT, the mean duration of LC was 47.9 (range 5.1-60.2) months. LC at 1,3 and 5 years was $93.8 \%, 58.6 \%$ and $58.6 \%$, respectively. The median OS was 31.6 (range, $5.1 \sim 60.2$, average 34.3 ) months. OS at 1-, 3 - and 5 -years was $72.3 \%, 36.3 \%$ and $18.1 \%$, respectively. For those who had received EBRT twice or three times, the mean duration of LC was 20.8 (range 2.1-52.2) months. LC at 1, 3 and 5 years was $42.4 \%, 25.5 \%$ and $0 \%$, respectively. The median OS was 9.2 (range, $2.1^{\sim} 33.4$, average 13.9) months. OS at 1 - and 3 -years was $31.2 \%$ and $0 \%$, respectively (Figure 4 ).

The use of 3D-PT might improve LC $(\mathrm{P}=0.078)$ though the statistically difference was less significant. For patients who used 3D-PT, the mean duration of LC was 39.1 (range 2.1-41.9) months. LC at 1 and 3 years was $92.9 \%$ and $92.9 \%$, respectively. For those who did not use 3D-PT, the mean duration of LC was 29.2 (range 2.1-60.2) months. LC at 1 and 2 years was $61.5 \%$ and $29.5 \%$, respectively.

\subsection{Toxicities}

Common late adverse effects were mainly skin/mucosal toxicities. There were 2 cases of late severe adverse effects (6.5\%), including one case of grade 4 mandibular osteonecrosis and one case of grade 3 skin/mucosal toxicity. The patient suffered from mandibular osteonecrosis had received two courses of EBRT before last recurrence, of which the total dose accumulated to 138Gy. Another patient suffered from grade 3 skin/mucosal toxicity had received one course of EBRT for a total dose of 70Gy. Besides, eleven patients (41.9\%) suffered from late grade 1-2 adverse effects, including ten cases (32.2\%) of skin/mucosal toxicities and one case (3.2\%) of pain.

\section{Discussion}

With the development of treatments, only 10-20\% NPC patients would suffer local recurrence after initial treatment ${ }^{29-31}$. Surgery was one of options for recurrent NPC. In most retrospective studies, surgery has been reported to achieve a similar or better result than re-irradiation with a 5-year LC of $43-74 \%$ and a 5 -year OS of 47-62\% $\%^{9-13}$. Moreover, the advantage of surgery was fewer complications and better quality of life. 
However, it might be due to selected patients. The lesions considered resectable included rT1 disease, rT2-3 with limited parapharyngeal space involvement or disease confined to the base of sphenoid sinus. Others, such as involvement of the internal carotid artery, limited invasion to the clivus, posterior maxillary sinus, pterygoid process and petrous apex, might be resectable, which required the careful judgment by surgeon ${ }^{32}$. Therefore, there were still many patients not suitable or willing to receive surgical treatment, especially those with late-stage recurrence.

Reirradiation was the most common salvage treatment for recurrent NPC, especially for those unable to receive surgery ${ }^{18}$. However, previous studies have shown that recurrence usually occurred in high-dose areas with the characteristic of radio-resistance ${ }^{3334}$. Moreover, when finishing the first course of radiation, changes in the microenvironment such as fibrosis and vascular necrosis might exacerbate radio-resistance ${ }^{35}$. Reirradiation became a stuff work because of the balance of high dose needed for radio-resistance tumors and dose limited by accumulation of surrounding organs at risks. Previous studies have shown that the recurrent NPC patients with re-irradiation as a salvage treatment, LC and OS at 3 years can reach $70-89 \%$ and $46-58 \%$, respectively ${ }^{19-22}$. However, the side effects of reirradiation remain challenging issues. Virtually most patients with irradiation suffered long-term complications. About 30-70\% of patients were likely to develop severe (grade 3-5) complications ${ }^{202123-25}$. Moreover, some patients might die of fatal complications, such as necrosis of the temporal lobe necrosis, carotid blowout, teeth occlusion and mucosal ulcer ${ }^{26}[23,40,41]$. Han and colleagues ${ }^{21}$ reported that the prevalence of advanced toxicity (grade 3-5) of intensity modulated radiotherapy (IMRT)for treatment of recurrent NPC was $70.3 \%$, and that $69 \%$ of patients died of EBRT-related toxicity. Kong and co-workers ${ }^{19}$ reported that $29.3 \%$ patients died of radiotherapy-related complications. Of these patients, $23.9 \%$ patients died of massive hemorrhage, indicating that massive hemorrhage was the most common cause of death. $75 \%$ of patients underwent locally advanced disease. Koutcher and colleagues ${ }^{36}$ reported an incidence of $73 \%$ that grade III or above complications occurred. Teo and co-workers ${ }^{37}$ reported that the incidence of hearing loss or difficulty in opening mouth was approximately 50-70\% after reirradiation.

${ }^{125}$ I RSI-BT, one of the most common brachytherapy, was often chosen as a salvage treatment for recurrent cancers, such as hypopharyngeal carcinoma ${ }^{38}$, salivary gland carcinoma ${ }^{39}$ or other head and neck squamous cell carcinoma ${ }^{40}$. Because of its sharp dose curve, ${ }^{125}$ I RSI-BT could protect OARs and achieve a higher local dose distribution so as to achieve favorable LC. Many published studies ${ }^{40-46}$ have reported RSI-BT as a safe and effective treatment for recurrent NPC, with a local control probability at 1- and 3-years of 52-75.2\% and 5.3-73\%, respectively, and an overall survival probability at 1- and 3-years of 53-84.6\% and 6.7-39\%, respectively, as well as a accepted toxicities(Table 4).

In this retrospective analysis, LC of RSI-BT as a salvage treatment for recurrent NPC at 1-, 3- and 5-year was $71.3 \%, 41.9 \%$ and $27.9 \%$, respectively and OS at $1-, 3$ - and 5 -year was $57.7 \%, 23.8 \%$ and $11.9 \%$, respectively, which just the same as published studies.

We found that the total times of previous EBRT was a prognostic factor affecting $\mathrm{LC}(\mathrm{P}=0.001)$ and OS $(\mathrm{P}=0.012)$. For patients those received only once EBRT, LC at 1,3 and 5 years was $93.8 \%, 58.6 \%$ and $58.6 \%$, respectively and OS at 1 -, 3 - and 5 -years was $72.3 \%, 36.3 \%$ and $18.1 \%$, respectively. However, for those received EBRT twice or three times, LC at 1, 3 and 5 years was $42.4 \%, 25.5 \%$ and $0 \%$, respectively and OS at 1 - and 3 -years was $31.2 \%$ and $0 \%$, respectively. The results were probably due to fibrosis, atrophy and necrosis of local tissue, vascular redistribution, and decreased radio-sensitivity after multiple EBRT. Salvage treatment for local recurrent NPC after previous EBRT was a stuff task especially when the patient experienced twice or more courses of EBRT and RSI-BT might be alternative and promising.

We also found that sex was a key factor affecting $\mathrm{LC}(\mathrm{P}=0.037)$, which was not reported in previous work. It needs to be further investigated to exclude cause of the patient pool's unbalanced sex ratio males to females and small study cohort.

The use of 3D-PT might improve LC $(\mathrm{P}=0.078)$ though the statistically difference was less significant. 3D-PT was creatively designed and introduced into CT-guided RSI technique ${ }^{47}$. With 3D-PT assistance, RSI-BT may be more accurate and have better doses distribution which close to expected preoperative plan ${ }^{48}$. It 
provided a way of RSI-BT to standardization and normalization. An ideal dose distribution may lead to a better LC, but we can only identify the tendency due to our limited case number and still need more data to confirm it.

KPS was a prognostic factor to $\mathrm{LC}(\mathrm{P}=0.033)$ and might be a prognostic factor to $\mathrm{OS}(\mathrm{P}=0.075)$ though the statistically difference was less significant, which might have been due to the small study cohort or confounding factors. However, this prognostic factor needed more data to verify.

Furthermore, safety was another key point needed to be paid attention to. Comparing to EBRT, RSI-BT has the advantage of providing a small radius of radiation, high local radiation dose, sharp fall-off of the radiation dose and few radiation effects on adjacent tissues. These features achieve the goal of Precise EBRT and ${ }^{125} \mathrm{I}$ RSI-BT been recommended for treatment of several types of recurrent or relapsed cancer by the National Comprehensive Cancer Network. In our study, only 2 cases (6.5\%) suffered severe radiotoxicity: 1 case with of grade $3 \mathrm{skin} /$ mucosal toxicity and another of mandibular osteonecrosis. Besides, eleven patients $(41.9 \%)$ suffered from late grade 1-2 adverse effects, including ten cases (32.2\%) of skin/mucosal toxicities and one case $(3.2 \%)$ of pain. The prevalence of severe toxic and side effects observed in our study was obviously lower than that of patients receiving reirradiation for recurrent NPC in other studies, and further demonstrated the safety of ${ }^{125}$ I RSI-BT for treatment of recurrent NPC.

\section{Conclusion}

Our retrospective study demonstrated that ${ }^{125}$ I seed implantation was a safe, feasible and effective treatment option for treatment of recurrent NPC. The efficacy and safety of this method needs to be verified by randomized controlled studies with large study cohorts.

\section{References:}

1 Torre LA, Bray F, Siegel RL, Ferlay J, Lortet-Tieulent J, Jemal A. Global cancer statistics, 2012. CA Cancer J Clin . 2015-03-01 2015;65(2):87-108.

2 Shield KD, Ferlay J, Jemal A, et al. The global incidence of lip, oral cavity, and pharyngeal cancers by subsite in 2012. CA Cancer J Clin . 2017-01-01 2017;67(1):51-64.

3 Tuan JK, Ha TC, Ong WS, et al. Late toxicities after conventional radiation therapy alone for nasopharyngeal carcinoma. Radiother Oncol . 2012-09-01 2012;104(3):305-311.

4 Yeh SA, Tang Y, Lui CC, Huang YJ, Huang EY. Treatment outcomes and late complications of 849 patients with nasopharyngeal carcinoma treated with radiotherapy alone. Int J Radiat Oncol Biol Phys . 2005-07-01 2005;62(3):672-679.

5 Lee AW, Poon YF, Foo W, et al. Retrospective analysis of 5037 patients with nasopharyngeal carcinoma treated during 1976-1985: overall survival and patterns of failure. Int J Radiat Oncol Biol Phys . 1992-01-19 1992;23(2):261-270.

6 Setton J, Han J, Kannarunimit D, et al. Long-term patterns of relapse and survival following definitive intensity-modulated radiotherapy for non-endemic nasopharyngeal carcinoma. Oral Oncol . 2016-02-01 2016;53:67-73.

7 Peng G, Wang T, Yang KY, et al. A prospective, randomized study comparing outcomes and toxicities of intensity-modulated radiotherapy vs. conventional two-dimensional radiotherapy for the treatment of nasopharyngeal carcinoma. Radiother Oncol . 2012-09-01 2012;104(3):286-293.

8 Sun X, Su S, Chen C, et al. Long-term outcomes of intensity-modulated radiotherapy for 868 patients with nasopharyngeal carcinoma: an analysis of survival and treatment toxicities. Radiother Oncol . 2014-03-01 2014;110(3):398-403.

9 Wei WI. Salvage surgery for recurrent primary nasopharyngeal carcinoma. Crit Rev Oncol Hematol . 200002-01 2000;33(2):91-98. 
10 Fee WJ, Moir MS, Choi EC, Goffinet D. Nasopharyngectomy for recurrent nasopharyngeal cancer: a 2to 17-year follow-up. Arch Otolaryngol Head Neck Surg . 2002-03-01 2002;128(3):280-284.

11 King WW, Ku PK, Mok CO, Teo PM. Nasopharyngectomy in the treatment of recurrent nasopharyngeal carcinoma: a twelve-year experience. Head Neck . 2000-05-01 2000;22(3):215-222.

12 Vlantis AC, Chan HS, Tong MC, Yu BK, Kam MK, van Hasselt CA. Surgical salvage nasopharyngectomy for recurrent nasopharyngeal carcinoma: a multivariate analysis of prognostic factors. Head Neck . 2011-08-01 2011;33(8):1126-1131.

13 Chan JY. Surgical management of recurrent nasopharyngeal carcinoma. Oral Oncol . 2014-10-01 2014;50(10):913-917.

14 Leung TW, Tung SY, Sze WK, Sze WM, Wong VY, O SK. Salvage brachytherapy for patients with locally persistent nasopharyngeal carcinoma. Int J Radiat Oncol Biol Phys . 2000-05-01 2000;47(2):405-412.

15 Li JX, Lu TX, Huang Y, Han F. Clinical characteristics of recurrent nasopharyngeal carcinoma in highincidence area.Scientific WorldJournal . 2012-01-20 2012;2012:719754.

16 Oksuz DC, Meral G, Uzel O, Cagatay P, Turkan S. Reirradiation for locally recurrent nasopharyngeal carcinoma: treatment results and prognostic factors. Int J Radiat Oncol Biol Phys . 2004-10-01 2004;60(2):388394.

17 Hwang JM, Fu KK, Phillips TL. Results and prognostic factors in the retreatment of locally recurrent nasopharyngeal carcinoma. Int J Radiat Oncol Biol Phys . 1998-07-15 1998;41(5):1099-1111.

18 Qiu S, Lu J, Zheng W, et al. Advantages of intensity modulated radiotherapy in recurrent T1-2 nasopharyngeal carcinoma: a retrospective study.Bmc Cancer . 2014-11-03 2014;14:797.

19 Kong F, Zhou J, Du C, et al. Long-term survival and late complications of intensity-modulated radiotherapy for recurrent nasopharyngeal carcinoma.Bmc Cancer . 2018-11-20 2018;18(1):1139.

20 Hua YJ, Han F, Lu LX, et al. Long-term treatment outcome of recurrent nasopharyngeal carcinoma treated with salvage intensity modulated radiotherapy. Eur J Cancer . 2012-12-01 2012;48(18):3422-3428.

21 Han F, Zhao C, Huang SM, et al. Long-term outcomes and prognostic factors of re-irradiation for locally recurrent nasopharyngeal carcinoma using intensity-modulated radiotherapy. Clin Oncol ( $R$ Coll Radiol) . 2012-10-01 2012;24(8):569-576.

22 Xiao W, Liu S, Tian Y, et al. Prognostic significance of tumor volume in locally recurrent nasopharyngeal carcinoma treated with salvage intensity-modulated radiotherapy. Plos One . 2015-01-20 2015;10(4):e125351.

23 Han F, Zhao C, Huang SM, et al. Long-term outcomes and prognostic factors of re-irradiation for locally recurrent nasopharyngeal carcinoma using intensity-modulated radiotherapy. Clin Oncol ( $R$ Coll Radiol) . 2012-10-01 2012;24(8):569-576.

24 Ho AS, Zumsteg ZS, Meyer A, et al. Impact of Flap Reconstruction on Radiotoxicity After Salvage Surgery and Reirradiation for Recurrent Head and Neck Cancer. Ann Surg Oncol . 2016-12-01 2016;23(Suppl 5):850857.

25 Chan OS, Sze HC, Lee MC, et al. Reirradiation with intensity-modulated radiotherapy for locally recurrent T3 to T4 nasopharyngeal carcinoma.Head Neck . 2017-03-01 2017;39(3):533-540.

26 Eekers D, Roelofs E, Jelen U, et al. Benefit of particle therapy in re-irradiation of head and neck patients. Results of a multicentric in silico ROCOCO trial. Radiother Oncol . 2016-12-01 2016;121(3):387-394.

27 Wang JJ, Yuan HS, Li JN, Jiang YL, Tian SQ, Yang RJ. CT-guided radioactive seed implantation for recurrent rectal carcinoma after multiple therapy.Med Oncol . 2010-06-01 2010;27(2):421-429. 
28 Cox JD, Stetz J, Pajak TF. Toxicity criteria of the Radiation Therapy Oncology Group (RTOG) and the European Organization for Research and Treatment of Cancer (EORTC). Int J Radiat Oncol Biol Phys . 1995-03-30 1995;31(5):1341-1346.

29 Lee AW, Ma BB, Ng WT, Chan AT. Management of Nasopharyngeal Carcinoma: Current Practice and Future Perspective. J Clin Oncol . 2015-10-10 2015;33(29):3356-3364.

30 Chua M, Wee J, Hui EP, Chan A. Nasopharyngeal carcinoma. Lancet . 2016-03-05 2016;387(10022):10121024 .

$31 \mathrm{Au} \mathrm{KH}, \mathrm{Ngan} \mathrm{R}, \mathrm{Ng} \mathrm{A}$, et al. Treatment outcomes of nasopharyngeal carcinoma in modern era after intensity modulated radiotherapy (IMRT) in Hong Kong: A report of 3328 patients (HKNPCSG 1301 study). Oral Oncol . 2018-02-01 2018;77:16-21.

32 Lee A, Ng WT, Chan J, et al. Management of locally recurrent nasopharyngeal carcinoma. Cancer Treat Rev . 2019-09-01 2019;79:101890.

$33 \mathrm{Ng}$ WT, Lee MC, Hung WM, et al. Clinical outcomes and patterns of failure after intensity-modulated radiotherapy for nasopharyngeal carcinoma.Int J Radiat Oncol Biol Phys . 2011-02-01 2011;79(2):420-428.

34 Li JX, Huang SM, Jiang XH, et al. Local failure patterns for patients with nasopharyngeal carcinoma after intensity-modulated radiotherapy.Radiat Oncol . 2014-03-27 2014;9:87.

35 Li JC, Hu CS, Jiang GL, et al. Dose escalation of three-dimensional conformal radiotherapy for locally recurrent nasopharyngeal carcinoma: a prospective randomised study. Clin Oncol ( $R$ Coll Radiol) . 2006-0501 2006;18(4):293-299.

36 Koutcher L, Lee N, Zelefsky M, et al. Reirradiation of locally recurrent nasopharynx cancer with external beam radiotherapy with or without brachytherapy. Int J Radiat Oncol Biol Phys . 2010-01-01 2010;76(1):130137.

37 Teo PM, Kwan WH, Chan AT, Lee WY, King WW, Mok CO. How successful is high-dose (\&gt; or = 60 Gy) reirradiation using mainly external beams in salvaging local failures of nasopharyngeal carcinoma? Int J Radiat Oncol Biol Phys . 1998-03-01 1998;40(4):897-913.

$38 \mathrm{Li}$ L, Yang J, Li X, et al. (125)I Seed Permanent Implantation as a Palliative Treatment for Stage III and IV Hypopharyngeal Carcinoma. Clin Exp Otorhinolaryngol . 2016-09-01 2016;9(3):185-191.

39 Liu SM, Wang HB, Sun Y, et al. The efficacy of iodine-125 permanent brachytherapy versus intensitymodulated radiation for inoperable salivary gland malignancies: study protocol of a randomised controlled trial. Bmc Cancer . 2016-03-07 2016;16:193.

40 Ji Z, Jiang Y, Tian S, et al. The Effectiveness and Prognostic Factors of CT-guided Radioactive Iodine-125 Seed Implantation for the Treatment of Recurrent Head and Neck Cancer after External Beam Radiotherapy.Int J Radiat Oncol Biol Phys . 2018-11-01 2018.

41 Jiang YL, Meng N, Wang JJ, et al. CT-guided iodine-125 seed permanent implantation for recurrent head and neck cancers. Radiat Oncol . 2010-07-30 2010;5:68.

42 Zhu L, Jiang Y, Wang J, et al. An investigation of 125I seed permanent implantation for recurrent carcinoma in the head and neck after surgery and external beam radiotherapy. World J Surg Oncol . 201303-08 2013;11:60.

43 Shen X, Li Y, Zhang Y, Kong J, Li Y. An analysis of brachytherapy with computed tomography-guided permanent implantation of Iodine-125 seeds for recurrent nonkeratin nasopharyngeal carcinoma. Onco Targets Ther . 2015-01-20 2015;8:991-997.

44 Huang H, Xu S, Li F, Du Z, Wang L. Clinical application of computed tomography-guided (125)I seed 
interstitial implantation for head and neck cancer patients with unmanageable cervical lymph node metastases.Eur J Med Res . 2016-04-27 2016;21:18.

45 Yan H, Mo Z, Xiang Z, et al. CT-guided (125)I brachytherapy for locally recurrent nasopharyngeal carcinoma. J Cancer . 2017-01-20 2017;8(11):2104-2113.

46 Jiang P, Wang J, Ran W, Jiang Y, Tian S, Sun H. Five-year outcome of ultrasound-guided interstitial permanent (125)I seeds implantation for local head and neck recurrent tumors: a single center retrospective study. J Contemp Brachytherapy . 2019-02-01 2019;11(1):28-34.

47 Wang J, Zhang F, Guo J, et al. Expert consensus workshop report: Guideline for three-dimensional printing template-assisted computed tomography-guided (125)I seeds interstitial implantation brachytherapy. $J$ Cancer Res Ther . 2017-01-20 2017;13(4):607-612.

48 Ji Z, Jiang Y, Guo F, et al. Dosimetry verification of radioactive seed implantation for malignant tumors assisted by 3D printing individual templates and CT guidance. Appl Radiat Isot . 2017-06-01 2017;124:68-74.

\section{Figure legends}

Figure 1. Procedure of CT-guided RSI-BT as a salvage treatment for recurrent nasopharyngeal carcinoma after external beam radiotherapy.

OS, overall survival; LC, local control

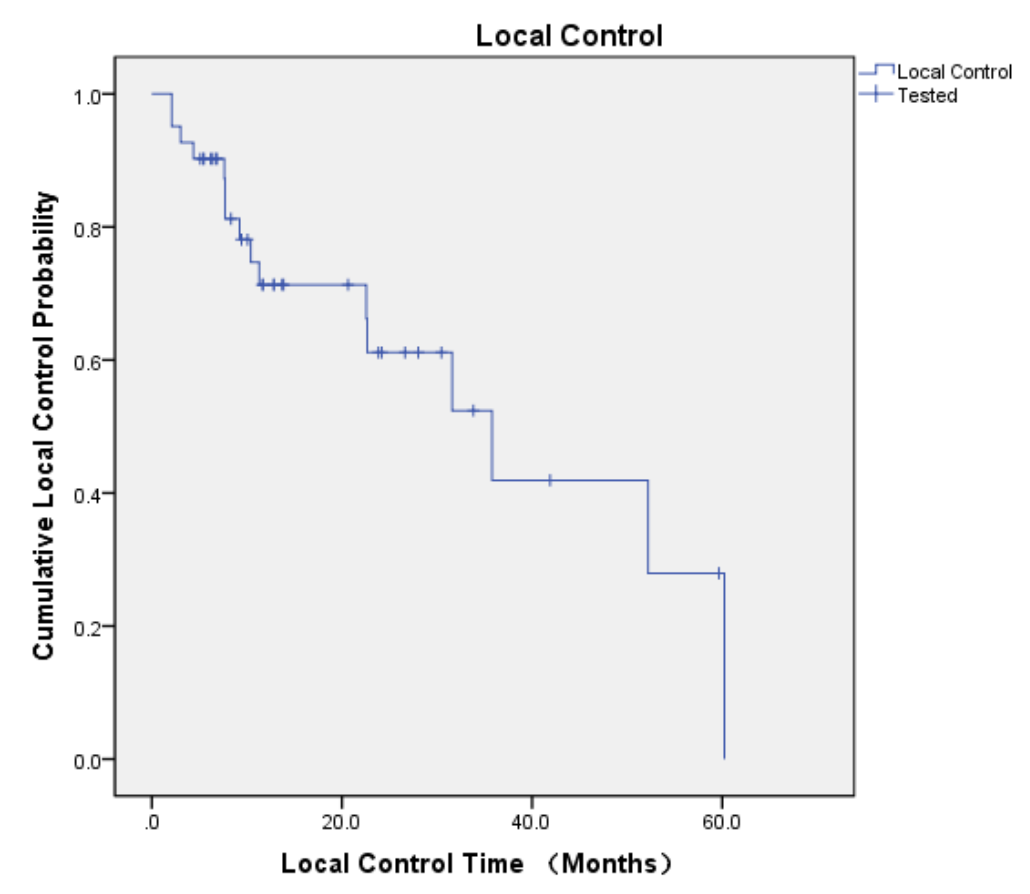

Figure 2. The local control for 41 lesions. 


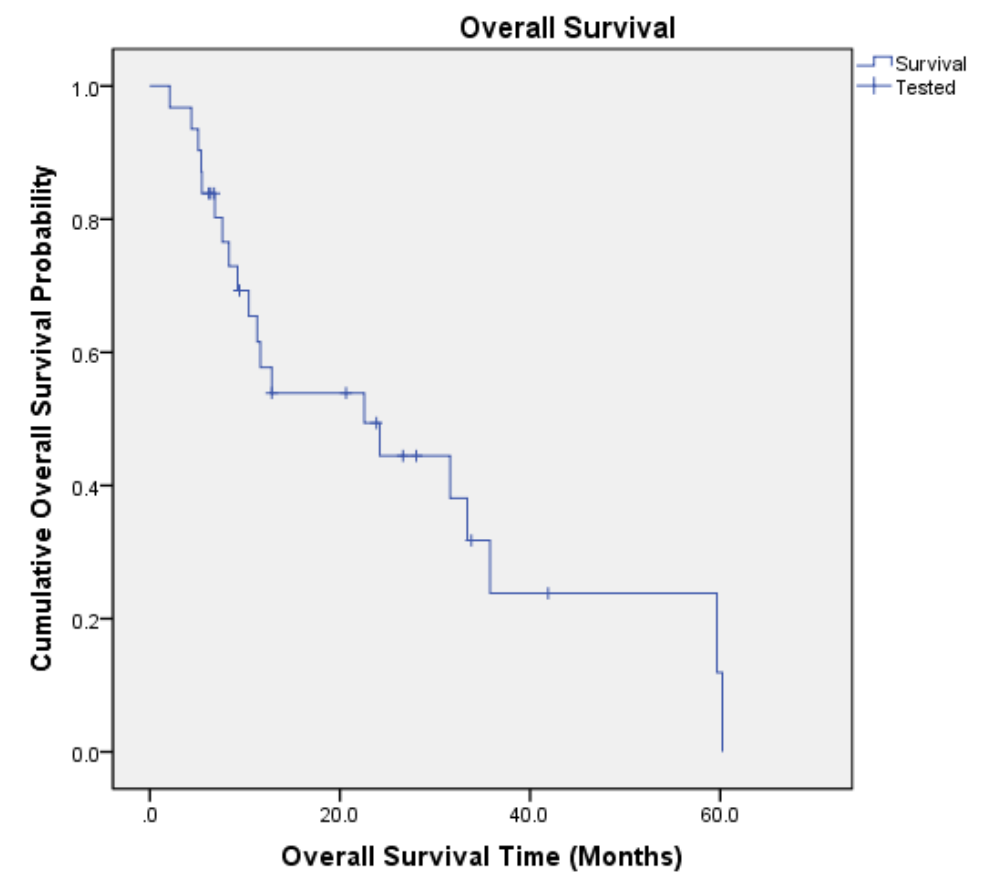

Figure 3. The overall survival for 31 patients.

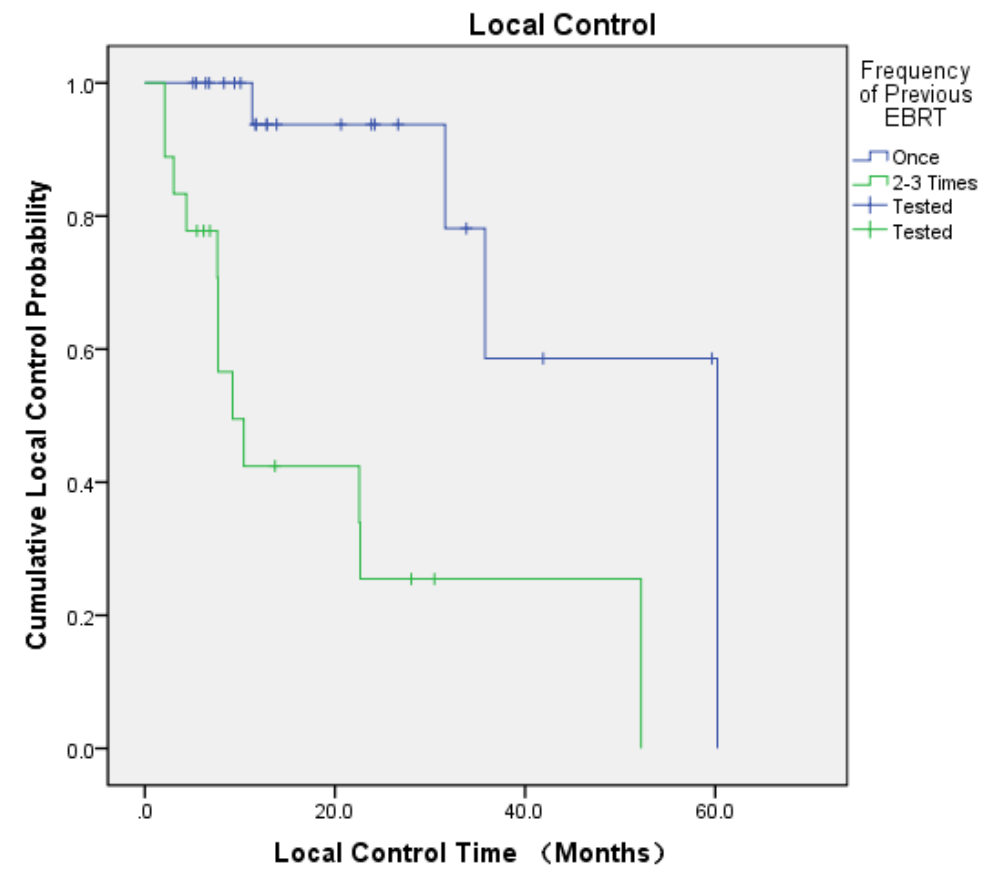

Figure 4. The local control and overall survival for patients treated with EBRT once and 2-3 times. 

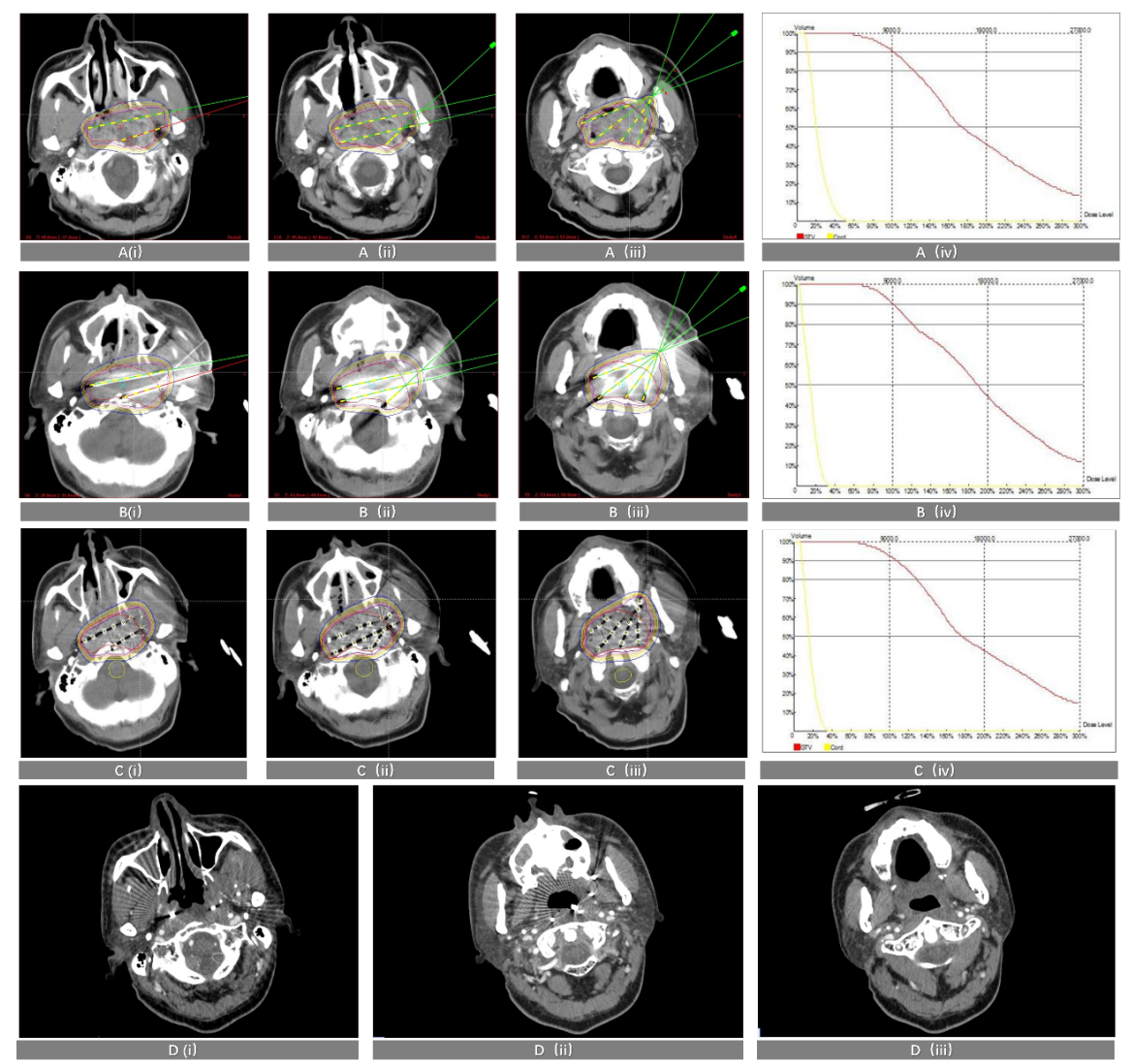

Figure 5. A 52-year-old male with nasopharyngeal undifferentiated non-keratinized carcinoma cT3N2M0 stage III has received sequential chemoradiotherapy, with included 70.4Gy/32fractions of external beam radiotherapy and four cycles of chemotherapy. Ten months after initial treatment, he suffered from recurrence. He decided to receive two cycles of chemotherapy and RSI-BT as a salvage treatment.

A. (i-iii) before RSI-BT, (iv) dose volume histograms (DVH) of RSI-BT; B. (i-iii) intraoperative needle puncture pathway, (iv) dose volume histograms (DVH) of RSI-BT; C. (i-iii) after RSI-BT, (iv) dose volume histograms (DVH) of RSI-BT. D. (i-iii) 2 months after RSI-BT.

Table 1. General information of the study cohort and their tumors

\begin{tabular}{lll}
\hline Characteristics & Cases & Percentage \\
\hline Sex & \multicolumn{2}{c}{} \\
Male & 20 & 64.5 \\
Female & 11 & 35.5 \\
Age: years, median (range) & $52(25-73)$ & \\
Karnofsky Performance Status: median (range) & $80(60-90)$ & \\
Pathologic types & & \\
Non-keratinizing & 17 & 54.8 \\
Squamous cell carcinoma & 14 & 45.2 \\
Previous EBRT frequency & & 64.5 \\
Once & 20 & 29.0 \\
Two times & 9 & 6.5
\end{tabular}




\begin{tabular}{lll}
\hline Characteristics & Cases & Percentage \\
\hline Total dose of previous EBRT: Median (Range) & $71.9(60-160)$ & \\
Previous surgery & 7 & 22.6 \\
Yes & 73 & 74.2 \\
No & 1 & 3.2 \\
Not known & & 74.2 \\
Previous chemotherapy & 23 & 25.8 \\
Yes & 8 & 22.6 \\
No & & 77.4 \\
Previous molecular targeted therapy & 7 & 45.2 \\
Yes & 24 & 54.8 \\
No & & \\
Recurrent sites & 14 & 17 \\
Lymph node & $19.6(2.1-113.3)$ \\
Time from the initial EBRT to implantation: months, median (range) & \\
\hline
\end{tabular}

EBRT, external beam radiotherapy

Table 2. Univariate analysis of LC for recurrent NPC

\begin{tabular}{|c|c|c|c|c|}
\hline & & Univariate analysis & Univariate analysis & Univar \\
\hline Variables & Categories & HR & $95 \% \mathrm{CI}$ & p-valu \\
\hline Sex & $\begin{array}{l}\text { Male } \\
\text { Female }\end{array}$ & 0.316 & $0.107-0.935$ & 0.037 \\
\hline Age (years) & $\begin{array}{l}{[?] 50} \\
i 50\end{array}$ & 1.828 & $0.648-5.157$ & 0.255 \\
\hline Pathology & $\begin{array}{l}\text { Non-keratinizing } \\
\text { Squamous }\end{array}$ & 0.840 & $0.502-1.405$ & 0.507 \\
\hline Previous EBRT times & $\begin{array}{l}1 \\
2-3\end{array}$ & 0.115 & $0.032-0.415$ & 0.001 \\
\hline Time from EBRT to RSI-BT (months) & $\begin{array}{l}{[?] 18} \\
i 18\end{array}$ & 1.733 & $0.573-5.243$ & 0.330 \\
\hline KPS & $\begin{array}{l}{[?] 80} \\
¡ 80\end{array}$ & 0.261 & $0.076-0.900$ & 0.033 \\
\hline Implantation Sites & $\begin{array}{l}\text { In situ } \\
\text { Lymph nodes }\end{array}$ & 2.517 & $0.782-8.108$ & 0.122 \\
\hline D90 (Gy) & $\begin{array}{l}\lceil 120 \\
{[?] 120}\end{array}$ & 1.126 & $0.383-3.314$ & 0.829 \\
\hline RSI-BT assistance & $\begin{array}{l}\text { Without 3D-PT } \\
\text { 3D-PT }\end{array}$ & 6.242 & $0.814-47.867$ & 0.078 \\
\hline Short-term efficacy & $\begin{array}{l}\mathrm{CR}+\mathrm{PR} \\
\mathrm{SD}+\mathrm{PD}\end{array}$ & 0.785 & $0.167-3.683$ & 0.759 \\
\hline
\end{tabular}

EBRT, external beam radiotherapy; HR, hazard ratio; CI, confidence interval; LC, local control; NPC, nasopharyngeal carcinoma; CR, complete response; PR, partial response; SD, stable disease; PD, progressive disease.

Table 3. Univariate analysis of OS for NPC 


\begin{tabular}{|c|c|c|c|c|}
\hline & & Univariate analysis & Univariate analysis & Univar \\
\hline Variables & Categories & HR & $95 \% \mathrm{CI}$ & p-value \\
\hline Sex & $\begin{array}{l}\text { Male } \\
\text { Female }\end{array}$ & 0.730 & $0.285-1.871$ & 0.512 \\
\hline Age (years) & $\begin{array}{l}{[?] 50} \\
i 50\end{array}$ & 0.742 & $0.277-1.984$ & 0.552 \\
\hline Pathology & $\begin{array}{l}\text { Non-keratinizing } \\
\text { Squamous }\end{array}$ & 0.813 & $0.321-2.062$ & 0.663 \\
\hline Previous EBRT times & $\begin{array}{l}1 \\
2-3\end{array}$ & 0.288 & $0.109-0.756$ & 0.012 \\
\hline Time from EBRT to RSI-BT (months) & $\begin{array}{l}{[?] 18} \\
\text { ¿18 }\end{array}$ & 0.899 & $0.348-2.322$ & 0.826 \\
\hline KPS & $\begin{array}{l}{[?] 80} \\
\vdots 80\end{array}$ & 0.367 & $0.122-1.108$ & 0.075 \\
\hline Implantation Sites & $\begin{array}{l}\text { In situ } \\
\text { Lymph nodes }\end{array}$ & 0.993 & $0.389-2.533$ & 0.988 \\
\hline D90 (Gy) & $\begin{array}{l}¡ 120 \\
{[?] 120}\end{array}$ & 0.837 & $0.299-2.346$ & 0.735 \\
\hline RSI-BT assistance & $\begin{array}{l}\text { Without 3D-PT } \\
\text { 3D-PT }\end{array}$ & 1.509 & $0.535-4.252$ & 0.437 \\
\hline Short-term efficacy & $\begin{array}{l}\mathrm{CR}+\mathrm{PR} \\
\mathrm{SD}+\mathrm{PD}\end{array}$ & 0.579 & $0.181-1.854$ & 0.357 \\
\hline
\end{tabular}

EBRT, external beam radiotherapy; HR, hazard ratio; CI, confidence interval; OS, overall survival; NPC, nasopharyngeal carcinoma; $\mathrm{CR}$, complete response; $\mathrm{PR}$, partial response; $\mathrm{SD}$, stable disease; $\mathrm{PD}$, progressive disease.

Table 4. Outcomes of published retrospective studies on RSI-BT as treatment for NPC

\begin{tabular}{|c|c|c|c|c|c|c|c|}
\hline Author & $\begin{array}{l}\text { No. of } \\
\text { patients }\end{array}$ & $\begin{array}{l}\text { Tumor } \\
\text { Volume }\end{array}$ & $\begin{array}{l}\text { Dose } \\
(\mathrm{Gy})\end{array}$ & $\begin{array}{l}\text { Median } \\
\text { follow up } \\
\text { (Months) }\end{array}$ & $\begin{array}{l}\text { Local } \\
\text { Control } \\
(\%)\end{array}$ & $\begin{array}{l}\text { Overall } \\
\text { Survival } \\
(\%)\end{array}$ & Toxicity \\
\hline $\begin{array}{l}\text { Yuliang } \\
\text { Jiang } \\
(2010)^{41}\end{array}$ & $14(3 \mathrm{NPC})$ & $\begin{array}{l}32(9.1- \\
290.4)\end{array}$ & $\begin{array}{l}157.5(90- \\
218)\end{array}$ & $12(3-60)$ & $\begin{array}{l}\text { Median } \\
18 \text { mo 1y } \\
52 \% 3 y 39 \% \\
5 y 39 \%\end{array}$ & $\begin{array}{l}\text { Median } \\
20 \mathrm{mo} 1 \mathrm{y} \\
65 \% 3 \mathrm{y} 39 \% \\
5 \mathrm{y} 39 \%\end{array}$ & $\begin{array}{l}1 \text { case } \\
\text { mucosal } \\
\text { reaction }\end{array}$ \\
\hline $\begin{array}{l}\text { Lihong Zhu } \\
(2013)^{42}\end{array}$ & 19 (1 NPC) & $20(1-270)$ & $131(90-160)$ & $11(3-44)$ & $\begin{array}{l}\text { Median } \\
24 \mathrm{mo} 1 \mathrm{y} \\
73.3 \% 2 \mathrm{y} \\
27.5 \% 3 \mathrm{y} \\
27.5 \%\end{array}$ & $\begin{array}{l}\text { Median } \\
13 \mathrm{mo} \mathrm{1y} \\
53.0 \% 2 \mathrm{y} \\
18.2 \% 3 \mathrm{y} \\
18.2 \%\end{array}$ & $\begin{array}{l}1 \text { case skin } \\
\text { reaction }\end{array}$ \\
\hline $\begin{array}{l}\text { Xinying } \\
\text { Shen } \\
(2015)^{43}\end{array}$ & 30 & $\begin{array}{l}\text { Diameter } \\
2.5 \pm 1.2 \mathrm{~cm} \\
(1.0-5.9)\end{array}$ & $130(90-160)$ & $2-38$ & $\begin{array}{l}1 \mathrm{y} 73.7 \% 2 \mathrm{y} \\
26.3 \% 3 \mathrm{y} \\
5.3 \%\end{array}$ & $\begin{array}{l}1 \mathrm{y} 80.0 \% 2 \mathrm{y} \\
30.0 \% 3 \mathrm{y} \\
6.7 \%\end{array}$ & NR \\
\hline $\begin{array}{l}\text { Hai Huang } \\
(2016)^{44}\end{array}$ & $31(9 \mathrm{NPC})$ & $\begin{array}{l}\text { Mean } \\
21.23 \pm 8.8\end{array}$ & $\begin{array}{l}\text { Mean } 101.03 \\
\text { Zz } 8.54 \\
(90-125)\end{array}$ & Range $6-38$ & $\begin{array}{l}\text { 1y } 64.51 \% \\
2 y 45.16 \%\end{array}$ & $\begin{array}{l}\text { 1y } 67.74 \% \\
2 y \quad 45.16 \%\end{array}$ & $\begin{array}{l}3 \text { cases G1 } 2 \\
\text { cases G2 }\end{array}$ \\
\hline $\begin{array}{l}\text { Huzheng } \\
\text { Yan } \\
(2017)^{45}\end{array}$ & $\begin{array}{l}81(39 \\
\text { RSI-BT) }\end{array}$ & NR & $120(100-140)$ & $30(5-68)$ & $\begin{array}{l}1 \mathrm{y} 71.7 \% 2 \mathrm{y} \\
41.0 \% 3 \mathrm{y} \\
23.1 \%\end{array}$ & $\begin{array}{l}1 \mathrm{y} 84.6 \% 2 \mathrm{y} \\
51.3 \% 3 \mathrm{y} \\
30.7 \%\end{array}$ & $\begin{array}{l}{[?] \mathrm{G} 325.6 \%} \\
\text { No G5 }\end{array}$ \\
\hline
\end{tabular}




\begin{tabular}{|c|c|c|c|c|c|c|c|}
\hline Author & $\begin{array}{l}\text { No. of } \\
\text { patients }\end{array}$ & $\begin{array}{l}\text { Tumor } \\
\text { Volume }\end{array}$ & $\begin{array}{l}\text { Dose } \\
(\mathrm{Gy})\end{array}$ & $\begin{array}{l}\text { Median } \\
\text { follow up } \\
\text { (Months) }\end{array}$ & $\begin{array}{l}\text { Local } \\
\text { Control } \\
(\%)\end{array}$ & $\begin{array}{l}\text { Overall } \\
\text { Survival } \\
(\%)\end{array}$ & Toxicity \\
\hline $\begin{array}{l}\text { Zhe Ji } \\
(2018)^{40}\end{array}$ & $\begin{array}{l}101(28 \\
\text { NPC) }\end{array}$ & $\begin{array}{l}15.5(2.4- \\
99.4)\end{array}$ & $117(44-246)$ & $\begin{array}{l}12.2(2.9- \\
73.2)\end{array}$ & $5 y 26.6 \%$ & 5y $15.5 \%$ & $\begin{array}{l}7.9 \% \text { G3 } 2 \% \\
\text { G4 }\end{array}$ \\
\hline $\begin{array}{l}\text { Ping Jiang } \\
(2019)^{46}\end{array}$ & 64 (12 NPC) & $\begin{array}{l}\text { Mean } \\
8 c c(2.5-320)\end{array}$ & $130(90-160)$ & $14(1-103.5)$ & $\begin{array}{l}1 \mathrm{y} 75.2 \% 3 \mathrm{y} \\
73.0 \% 5 \mathrm{y} \\
69.1 \%\end{array}$ & $\begin{array}{l}1 \mathrm{y} 57.4 \% 3 \mathrm{y} \\
31 \% 5 \mathrm{y} \\
26.6 \%\end{array}$ & $\begin{array}{l}2 \text { cases of } \\
\text { G4 skin } \\
\text { reaction; } \\
17 \% \text { G1-2 } \\
\text { skin reaction }\end{array}$ \\
\hline
\end{tabular}

NR, not reported.

\section{Hosted file}

Figure.pptx available at https://authorea.com/users/380119/articles/496212-efficacy-andprognosis-of-ct-guided-of-125i-radioactive-seeds-implantation-brachytherapy-as-salvagetreatment-for-recurrent-nasopharyngeal-carcinoma-after-external-beam-radiotherapy-along-term-experience-at-a-single-institution

\section{Hosted file}

Table.pdf available at https://authorea.com/users/380119/articles/496212-efficacy-andprognosis-of-ct-guided-of-125i-radioactive-seeds-implantation-brachytherapy-as-salvagetreatment-for-recurrent-nasopharyngeal-carcinoma-after-external-beam-radiotherapy-along-term-experience-at-a-single-institution 